\title{
Validation of a flow cytometry-based assay for monitoring complement-dependent cytotoxicity of an anti-CD20 biosimilar candidate antibody
}

\author{
Rancés Blanco-Santana*, Mercedes Cedeńo-Arias, Zulia García-Pérez, \\ Dayana Columbié-Gilbert, Alejandro Portillo-Vaquer, Enrique Rengifo-Calzado \\ Department of Quality Control, Center of Molecular Immunology, Havana, Cuba \\ *Corresponding author: rances@cim.sld.cu
}

\begin{abstract}
Appropriate validation of any bioassay to be used in the characterization of biological products is critical. In this study, we report a validation study of a flow cytometry-based assay to measure the complement-dependent cytotoxicity (CDC) of a biosimilar candidate monoclonal antibody (Mab) directed to CD20 antigen, as indicative of its biological activity. The assay was validated by examining: assay robustness, specificity, repeatability and intermediate precision. It demonstrated to be robust for all factors evaluated. It also showed a high level of specificity and was found to be free of interference through the validation process. The degree of precision (Cvs $<7 \%$ ) obtained in this study was satisfactory. The presented work demonstrated that a flow cytometry-based cytotoxicity assay is a suitable method in the lot to lot quality control monitoring of the culture supernatant and an active pharmaceutical ingredient of 1B8 Mab.
\end{abstract}

Key words: flow cytometry, complement-dependent cytotoxicity, validation study, therapeutic anti-CD20 Mab, Biosimilar

\section{Introduction}

Rituximab (IDEC-C2B8, Mabthera ${ }^{\circledR}$, Rituxan ${ }^{\circledR}$, Genentech, Inc.) is a recombinant monoclonal antibody (Mab) directed against the human B-cell differentiation specific antigen $\mathrm{CD} 20$. It was the first monoclonal antibody approved by the Food and Drug Administration (FDA) for the treatment of indolent B-cell non-Hodgkin's lymphoma (NHL). However, its application has been significantly extended as it can be used for virtually any CD20-positive NHL. More recently, Rituximab was also used in the treatment of other health conditions, such as autoimmune disorders (Smith, 2003).

The first generation of biological drugs that have introduced many revolutionary treatments to life-threatening and rare illnesses are currently facing patent expiration. Consequently, research-based and generics pharmaceutical companies alike are pursuing the opportunity to develop "generic" substitutes to original biologics, which are also known as biosimilars (Chu, 2009). An anti-CD20 biosimilar candidate Mab has been generated at the Center of Molecular Immunology, Havana, Cuba.
This Mab is capable of inducing complement-dependent cytotoxicity (CDC), antibody-dependent cell-mediated cytotoxicity (ADCC) as well as apoptosis in a variety of human cell lines with high levels of CD20 expression. The in vitro biological activity of the anti-CD20 biosimilar candidate Mab was comparable with those from the innovator product (Rituximab). These properties make this kind of Mab potentially useful and its evaluation in future clinical trials is recommended (Dorvignit et al., 2012).

Traditionally, the cytotoxic activity of Mabs has been evaluated by means of: 1) the release of radioactive isotopes (e.g. $\left[{ }^{51} \mathrm{Cr}\right]$ ) or fluorescence dyes from pre-labeled target cells, 2) the measurement of cytoplasmic enzyme activities released by damaged cells (e.g., lactate dehydrogenase, $\mathrm{LDH}$ ), and 3) the determination of plasmamembrane damage, based on the differential uptake or exclusion of dyes (e.g., trypan blue, propidium iodide) (Winiarska et al., 2008; Dorvignit et al., 2012). In this sense, the flow cytometry provides a rapid, non-radioactive and highly sensitive methodology that permits efficient detection of changes in the cell membrane in- 
tegrity (Blanco et al., 2012). Therefore, flow cytometry may be considered a useful tool for estimating the percentage of dead cells in a variety of cytotoxicity bioassays (Fernández-Marrero et al., 2011), including CDC (Dorvignit et al., 2012).

The use of accurate and well-characterized assays for testing biological products is vital for their development as therapeutic drugs (ICH, 1999, Cedeńo-Arias et al., 2011). Additionally, the assay which is employed to indicate biological activity of any biotechnological drug "should be based on the intended biological effect which should, ideally, be related to the clinical response" (EMEA, 2008). In this study, we report for the first time a validation study (assay robustness, specificity and precision) of a flow cytometry-based assay intended to measure the $\mathrm{CDC}$ of a biosimilar candidate Mab directed to CD20 antigen. The study was performed according to the International Conference on Harmonization (ICH) guidelines (ICH, 2005).

\section{Materials and Methods}

\section{Antibodies, reagents and sample preparation}

Rituximab (Mabthera ${ }^{\circledR}$, Roche) and a biosimilar 1B8 Mab (Center of Molecular Immunology, Cuba) were used for the study. Different samples of 1B8 were analyzed, including culture supernatant, an active pharmaceutical ingredient, and the final formulation of the purified product. The internal reference standard of 1B8 Mab was also included. As Mab-free matrix samples, both the batch of the buffer solution (used in the final formulation of purified product) and the complete cell culture media (used in the fermentation process) were employed. Two different humanized IgG1 Mabs were used as isotype controls (irrelevant Mabs): itolizumab (anti-CD6 Mab at $5.0 \mathrm{mg} / \mathrm{ml}$ ) manufactured by Biocon (India) and an active pharmaceutical ingredient of nimotuzumab (anti-epidermal growth factor receptor) produced by the Center of Molecular Immunology (Cuba). Degraded samples of $1 \mathrm{~B} 8 \mathrm{Mab}$ were prepared by incubation at $60^{\circ} \mathrm{C}$ for $168 \mathrm{~h}$. All Mabs were kept at $2-8^{\circ} \mathrm{C}$ until further use.

The working concentration of each sample $(100.0 \mu \mathrm{g} / \mathrm{ml}, 10.0 \mu \mathrm{g} / \mathrm{ml}$ and $1.0 \mu \mathrm{g} / \mathrm{ml})$ was obtained by serial dilutions from the stock solution $(5.0 \mathrm{mg} / \mathrm{ml}$. All samples were prepared fresh prior to the assay, and diluted with RPMI-1640 growth medium (PAA, Austria) containing $1 \%$ of fetal bovine serum (FBS) (PAA, Austria). As a source of human complement, serum samples from blood with different $\mathrm{ABO}$ groups and $\mathrm{Rh}$ factor expression were used. Blood samples were obtained from volunteer donors. The sera were stored at $-40^{\circ} \mathrm{C}$ until further use. Only freshly thawed sera diluted with RPMI-1640 containing 1\% FBS were used in the CDC assays.

\section{Cell line and culture conditions}

The human Burkitt's lymphoma derived cell line, Ramos (CRL-1596 ${ }^{\mathrm{TM}}$ ), was obtained from the American Type Culture Collection (ATCC, Rockville, MD). Cells were cultured in a complete growth medium RPMI-1640, supplemented with $10 \%$ FBS under standard conditions $\left(37^{\circ} \mathrm{C}\right.$ in humidified atmosphere containing $\left.5 \% \mathrm{CO}_{2}\right)$. Cultures were continued by additions of a fresh complete growth medium, maintaining the cell density between $2 \times 10^{5}$ and $1 \times 10^{6}$ viable cells $/ \mathrm{ml}$. The percentage of cell viability as well as the concentration of each cell suspension was calculated by trypan blue exclusion assay (Blanco et al., 2012). In all the CDC experiments, only cell suspensions with more than $80 \%$ of cell viability were used.

\section{Complement-dependent cytotoxicity assay}

For cytotoxicity survey, the previously described method by Dorvignit et al. (2012) was used with minor modifications. The nominal assays were performed as following: cells $\left(0.25 \times 10^{6}\right)$ were incubated with the anti$\mathrm{CD} 20 \mathrm{Mab}$ in a drug dilution medium $\left(1 \mathrm{~h}\right.$ at $\left.37^{\circ} \mathrm{C}\right)$. Thereafter, samples were treated with human $\mathrm{AB}$ serum (diluted 1:10) as a source of complement and incubated for $1 \mathrm{~h}$ at $37^{\circ} \mathrm{C}$. Then, the cells were washed with FACSFlow (BD, USA), centrifuged $\left(10 \mathrm{~min}\right.$ at $4^{\circ} \mathrm{C}$, $246 \times g)$ and re-suspended in FACSFlow. All samples were maintained in an ice bath and just before the FACS analysis, they were stained with propidium iodide (PI) (Sigma, USA) at a final concentration of $4 \mu \mathrm{g} / \mathrm{ml}$.

The percentage of non-viable cells was measured using the FACScan flow cytometer (BD, USA). Cells stained in red with PI were considered as necrotic, while viable cells showed no red fluorescence. The response to the treatment with itolizumab (an irrelevant Mab) was considered as spontaneous cell death (spontaneous lysis) while the response to Triton X-100 (a detergent that induces a non-selective permeabilization of cell membranes) action was taken as the maximal activity 
Table 1. Factors and experimental conditions evaluated in robustness assays

\begin{tabular}{c|l|c|c}
\hline \multirow{2}{*}{ Serie } & \multicolumn{2}{|c|}{ Factors } & \multicolumn{2}{c}{ Experimental conditions } \\
\cline { 3 - 4 } & & low level (-) & high level (+) \\
\hline A & Cell subculture & $1-19$ & $\geq 20$ \\
\hline B & Cell concentration in culture & $0.2-1 \times 10^{6}$ & $1-2 \times 10^{6}$ \\
\hline C & Cell concentration in assay & $2 \times 10^{5}$ & $3 \times 10^{5}$ \\
\hline D & Incubation time of Mab & $55 \mathrm{~min}$ & $65 \mathrm{~min}$ \\
\hline E & Dilution of complement & $1: 4$ & $1: 6$ \\
\hline F & Incubation time with complement & $55 \mathrm{~min}$ & $65 \mathrm{~min}$ \\
\hline
\end{tabular}

Mab - monoclonal antibody; min - minutes

(total lysis). The level of specific cytotoxicity was calculated according to the following formula: \% of specific cytotoxicity $=($ sample lysis - spontaneous lysis itolizumab $) /($ total $\operatorname{lysis}_{\text {TritonX-100 }}-$ spontaneous lysis itolizumab $\left._{1}\right) \times 100$. Finally, the result for each sample was reported as a percentage of relative cytotoxicity measured against the internal reference standard. The percentage of relative cytotoxicity was calculated as follows: $\%$ of relative cytotoxicity $=$ (\% of specific cytotoxicity sample ) / (\% of relative cytotoxi$\left.\mathrm{city}_{\text {internal reference standard }}\right) \times 100$.

\section{Robustness}

A Plackett-Burman design (Vander et al., 2001) for 7 factors (8 experiments) was performed (Table 1). For each factor, the nominal level such as in a regular assay was assumed and the extreme level (- or + ) was considered as a level deviation from the nominal assay. All experiments were performed in a randomized order and carried out in a short span of time (two days). Two experimental blocks including four assays each: B-I (experiments 2, 4, 5 and 6) and B-II (experiments 1, 3, 7 and 8) were confectioned. The assays of B-I were carried out using cells with 1 to 19 subcultures, while the experiments of B-II were performed using cells with more than 20 subcultures.

Additionally, the potential impact of different sources of human complement in the percentage of relative cytotoxicity of 1B8 Mab was evaluated. This study was performed using blood from five volunteer donors with diverse $\mathrm{ABO}$ groups and $\mathrm{Rh}$ factor expression. The serum corresponding to $\mathrm{AB}$ blood group served as the control (Table 5). Moreover, to study the potential bias caused by the consecution, a randomized assay was performed for the analysis of the samples in flow cytometry.

\section{Specificity}

The ability of the assay to measure the analyte unequivocally in the presence of other components in the sample was evaluated. The potential matrix interference was studied using the complete cell culture medium as well as the buffer formulation, used in the fermentation and formulation processes of $1 \mathrm{~B} 8 \mathrm{Mab}$, respectively. Additionally, two irrelevant Mabs (isotype controls) and positive samples containing $1 \mathrm{~B} 8 \mathrm{Mab}$ (in culture supernatant, active pharmaceutical ingredient and final formulation of purified product) were assessed. An internal reference standard and degraded sample (final formulation of purified product incubated at $60^{\circ} \mathrm{C}$ for $168 \mathrm{~h}$ ) of 1B8 Mab were also evaluated. Two independent experiments were performed. In this case, the detection of dimeric and monomeric species of 1B8 Mab was performed by means of a gel filtration (high pressure liquid chromatography; HPLC) analysis. An HPLC system (Shimadzu, Japan) LC-2010 HT equipped with a system controller, a quaternary pump, an autosampler and a UVVisible detector at $280 \mathrm{~nm}$ was used. In all cases, the internal reference standard of 1B8 Mab served as the positive control.

\section{Precision (repeatability/reproducibility)}

Assay precision was determined in three independent experiments evaluating 1B8 Mab in culture supernatant and final formulation of a purified product. Each assay was assessed by six replicates of the drug over time within the same day (intra-assay repeatability) and on three different days (inter-day variation) as well as across individuals (inter-person variation). In order to calculate the assay precision, the average, standard deviation (SD) and the coefficient of variation (CV) as 

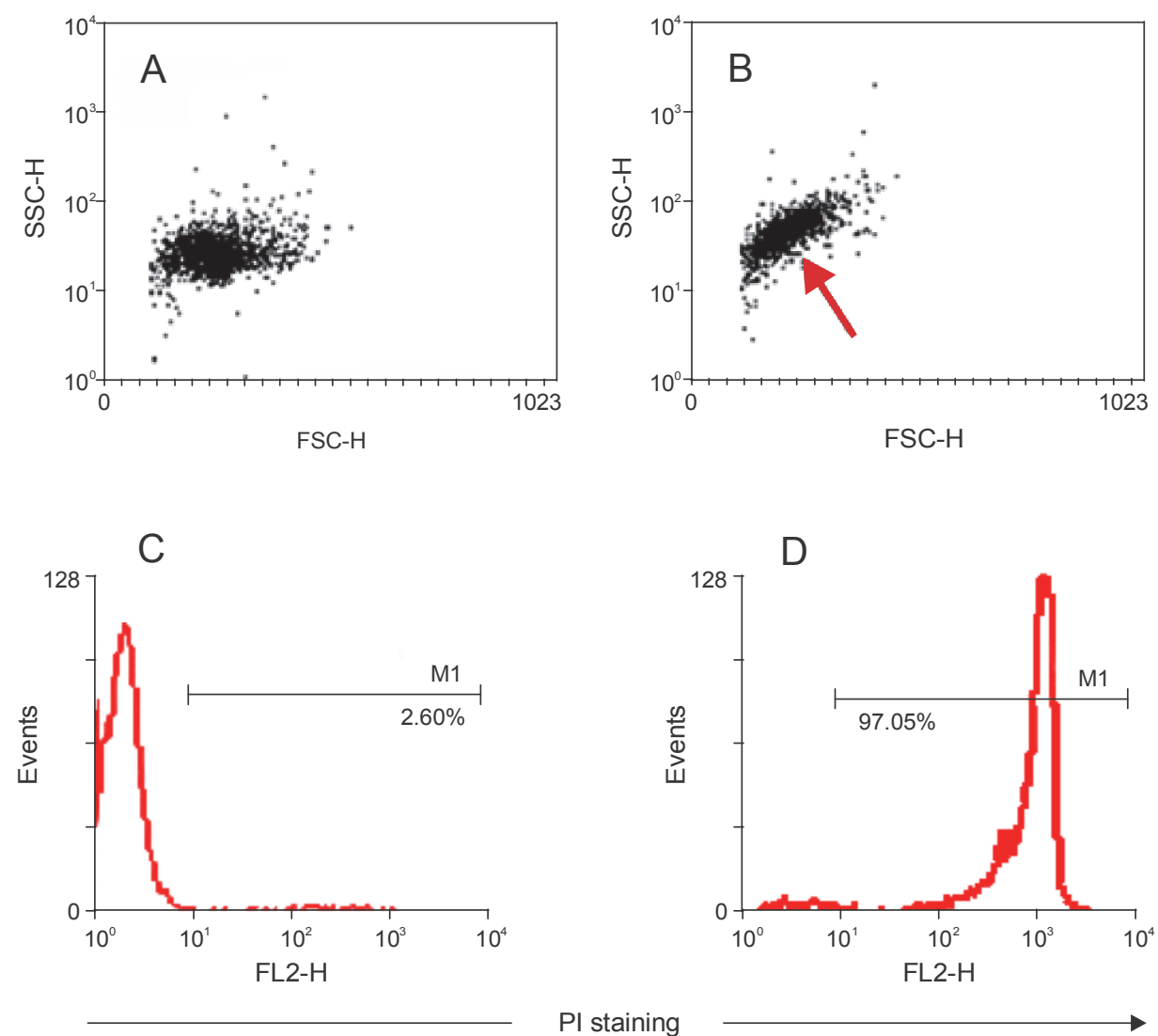

Fig. 1. Typical flow cytometric profiles of the complement-dependent cytotoxicity of 1B8 Mab in the human Burkitt's lymphoma derived cell line, Ramos. Dot plot graphs (A and B). Histogram graphs showing the discrimination of non-viable cells (M1) using the propidium iodide $(\mathrm{PI})$ staining $(\mathrm{C}$ and $\mathrm{D})$

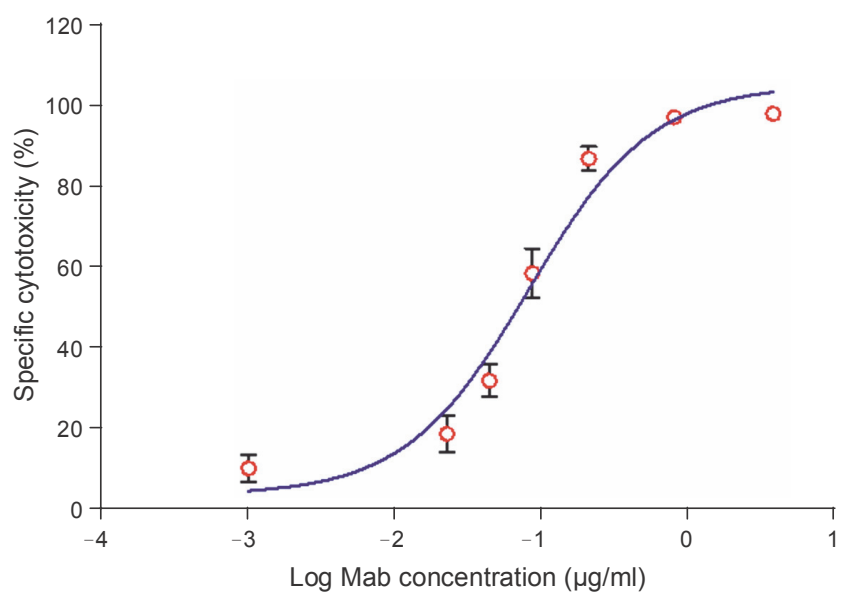

Fig. 2. Typical dose-response curve for the flow cytometrybased complement-dependent cytotoxicity assay using 1B8 Mab. The mean and standard deviations of three different experiments are shown

$[(\mathrm{SD} /$ average $) \times 100]$ were determined for each type of product.

\section{Data analysis}

All raw data were analyzed using WinMDI 2.8 free software (http://facs.scripps.edu/software.html). The data were plotted on FL2-H histograms and no gate was applied. The percentages of non-viable cells were obtained from the statistical report corresponding to each histogram. In the robustness assay, statistical and graphical analyses of the effects were performed for interpretation. Algorithm of Dong was used to identify the significant effects and a half-normal probability plot was drawn to indicate the visually relevant effects (Vander et al., 2001). For all assays, the average, SD and CV were calculated using Excel 2007 (Microsoft).

\section{Results and discussion}

In the biopharmaceutical industry, experiments should be based on generally accepted scientific principles, and appropriate controls should also be included to demonstrate that the experimental setup is working 
Table 2. Percentage of relative cytotoxicity of 1B8 Mab using Rituximab as standard

\begin{tabular}{l|c|c|c|c|c|c}
\hline \multicolumn{1}{c|}{ 1B8 Sample } & \multicolumn{2}{|c|}{ Relative cytotoxicity } & Mean & SD & CV \\
\hline Final formulation of purified product & 98.58 & 98.60 & 99.76 & 98.98 & 0.68 & 0.68 \\
\hline Internal reference standard & 100.06 & 99.57 & 99.64 & 99.76 & 0.27 & 0.27 \\
\hline
\end{tabular}

$\mathrm{RC}$ - average of relative cytotoxicity; SD - standard deviation; $\mathrm{CV}$ - coefficient of variation Results of three independent experiments

Table 3. Percentage of relative cytotoxicity of $1 \mathrm{~B} 8 \mathrm{Mab}$ in robustness assays

\begin{tabular}{|c|c|c|c|c|c|c|c|c|}
\hline \multirow{2}{*}{ Experiments } & \multicolumn{7}{|c|}{ Factors } & \multirow{2}{*}{$\mathrm{RC}$} \\
\hline & * & $\mathrm{D}$ & $\mathrm{F}$ & $\mathrm{E}$ & $\mathrm{C}$ & B & A & \\
\hline \multicolumn{8}{|c|}{ Nominal } & 100.11 \\
\hline 1 & + & + & + & - & + & - & - & 100.14 \\
\hline 2 & - & + & + & + & - & + & - & 99.99 \\
\hline 3 & - & - & + & + & + & - & + & 100.15 \\
\hline 4 & + & - & - & + & + & + & - & 100.40 \\
\hline 5 & - & + & - & - & + & + & + & 99.83 \\
\hline 6 & + & - & + & - & - & + & + & 99.33 \\
\hline 7 & + & + & - & + & - & - & + & 100.23 \\
\hline 8 & - & - & - & - & - & - & - & 100.74 \\
\hline
\end{tabular}

(+) - high level; (-) -, low level; * - Dummy factor; A - cell subculture; B - cell concentration in culture; $\mathrm{C}$ - cell concentration in assay; $\mathrm{D}$ - incubation time of Mab; $\mathrm{E}$ - dilution of complement; F - incubation time with complement; $\mathrm{RC}$ - relative cytotoxicity

Table 4. Effects of factors on the response of relative cytotoxicity of $1 \mathrm{~B} 8 \mathrm{Mab}$

\begin{tabular}{l|c}
\hline \multicolumn{1}{c|}{ Factors } & Effects \\
\hline Cell subculture & -0.43 \\
\hline Cell concentration in assay & -0.43 \\
\hline Incubation time with complement & -0.40 \\
\hline Cell concentration in culture & 0.06 \\
\hline Incubation time of Mab & 0.11 \\
\hline Dummy & 0.15 \\
\hline Dilution of complement & 0.18 \\
\hline Mean of modular values of effects & 0.18 \\
\hline
\end{tabular}

Experimental error estimated according algorithm of Dong

\begin{tabular}{l|l}
\hline $\mathrm{S}_{0}$ & 0.27 \\
\hline $2,5 \times \mathrm{S}_{0}$ & 0.68 \\
\hline $\mathrm{S}_{1}$ & 0.29 \\
\hline $\mathrm{ME}(\alpha=0.05)$ & 0.69 \\
\hline $\mathrm{ME}(\alpha=0.01$ & 1.01 \\
\hline
\end{tabular}

$\mathrm{S}_{0}$ - estimate of error; $\mathrm{S}_{1}$ - standard error; $\mathrm{ME}$ - margin of error 


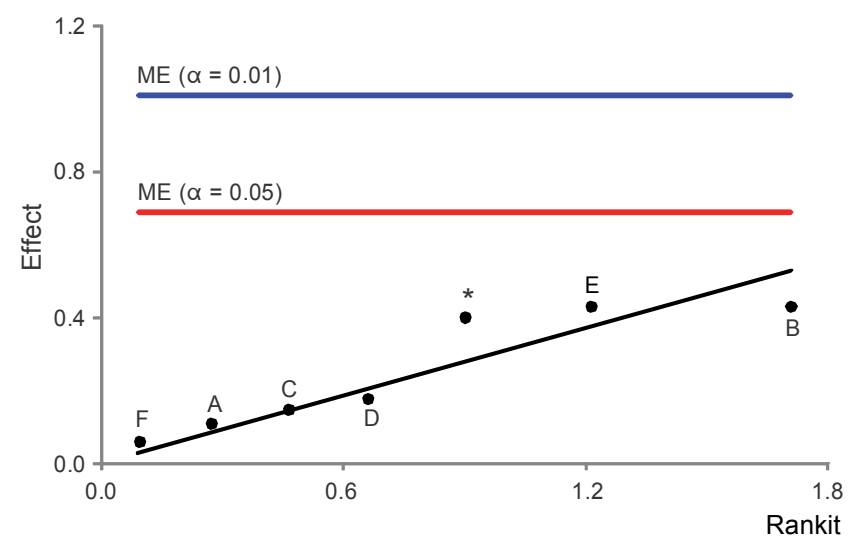

Fig. 3. Half-normal probability plot for the effects estimated in Plackett-Burman design for 7 factors (from Table 3). Dummy factor $\left({ }^{*}\right)$, cell subculture $(A)$, cell concentration in culture (B), cell concentration in assay (C), incubation time of $\mathrm{Mab}(\mathrm{D})$, dilution of complement $(\mathrm{E})$, incubation time with complement $(\mathrm{F})$

as expected (Ederveen, 2010). Based on the ICH guidelines (ICH, 2005), each analytical procedure must be validated with respect to parameters that are relevant to its performance (Findlay et al., 2000; Ermer, 2000).

Flow cytometry technology usually permits to discriminate cells of interest in a heterogeneous cell population, mainly based on the detection of their light scattering and fluorescence properties, including the cell surface integrity (Blanco et al., 2012). Moreover, flow cytometry provides a rapid and reliable method of discriminating living and dead cell populations (FernándezMarrero et al., 2011; Blanco et al., 2012; Dorvignit et al., 2012).

In our study, we used the staining of non-viable cells with PI (Abid et al., 2012). This method is a suitable tool to determine the $\mathrm{CDC}$ activity of $1 \mathrm{~B} 8 \mathrm{Mab}$, as it was previously tested (Dorvignit et al., 2012). Cells that actively uptake the dye fluoresced brightly in the red range of the visible color spectrum (Enter and Monson, 2005) - Figure 1. A similar flow cytometry-based CDC assay to Rituximab was considered a robust and sensitive assay avoiding the use of more complex methods (Herbrand and Scotti, 2007).

The optimum concentration of $1 \mathrm{~B} 8 \mathrm{Mab}$ to induce $\mathrm{CDC}$ was evaluated using a lymphoid cell line over-expressing CD20 antigen, Ramos (Fig. 2). The 1B8 Mab was able to induce CDC activity in a dose-dependent manner, obtaining the maximum of complement-dependent cytotoxicity $(\geq 90 \%)$ and less variability $(\mathrm{CV}<1 \%)$ at
$1.0 \mu \mathrm{g} / \mathrm{ml}$ of Mab. The value of relative cytotoxicity of 1B8 Mab (final formulations of purified product and internal reference standard) was assessed at a concentration of $1.0 \mu \mathrm{g} / \mathrm{ml}$, by comparing their biological response with Rituximab (the generic reference product) - Table 2. The relative cytotoxicity of 1B8 Mab using Rituximab as a standard was in the range of $85-115 \%$ for both final formulations of purified product and the internal reference standard. The CVs were $<1 \%$ which was considered acceptable. The presented results are in agreement with those obtained by Dorvignit et al. (2012), confirming that $\mathrm{CDC}$ is one of the mechanisms of biological activity of the 1B8 biosimilar candidate Mab, with similar activity to Rituximab (Herbrand and Scotti, 2007).

The robustness/ruggedness of an analytical procedure is a measure of its capacity to remain unaffected by small, but deliberate variations in parameters and provides an indication of its reliability during normal usage (ICH, 2005). The identification of the factors to be tested is the first step in any robustness design (Vander et al., 2001). Here, we investigated seven parameters using a Plackett-Burman design (Vander et al., 2001). The levels used for each factor as well as analytical responses are given in Table 3. In all robustness assays, similar to the nominal ones, the relative cytotoxicity of 1B8 Mab fulfilled the acceptance criteria (85-115\%). Statistical and graphical analyses of the effects of each factor were also performed for interpretation. The statistical analysis (see material and method section) and results are shown in Table 4 and plotted in Figure 3. In a half-normal plot, the non-significant effects tend to fall on a straight line through zero, while significant effects deviate from it (Vander et al., 2001). In our study, no significant effects were obtained (Fig. 3).

Table 5. Effects of type of blood group and Rh factor in the relative cytotoxicity of $1 \mathrm{~B} 8 \mathrm{Mab}$

\begin{tabular}{c|c|c}
\hline ABO blood group & Rh factor & $\mathrm{RC}$ \\
\hline $\mathrm{AB}$ & - & 100.39 \\
\hline $\mathrm{O}$ & + & 100.67 \\
\hline $\mathrm{A}$ & - & 101.17 \\
\hline $\mathrm{B}$ & - & 100.47 \\
\hline $\mathrm{A}$ & + & 100.14 \\
\hline $\mathrm{A}$ & + & 100.82 \\
\hline
\end{tabular}

$\mathrm{RC}$ - relative cytotoxicity; (-) - negative; $(+)$ - positive 
Table 6. Specificity data for $1 \mathrm{~B} 8 \mathrm{Mab}$ CDC assay

\begin{tabular}{l|l|c|c}
\hline \multicolumn{2}{c|}{ Samples } & RC & \multirow{2}{*}{$\begin{array}{c}\text { Acceptance } \\
\text { criteria }\end{array}$} \\
\hline \multirow{2}{*}{ Isotype Mab } & Nimotuzumab & 0.47 & \\
\hline \multirow{2}{*}{ Matrix } & Formulation buffer & \multirow{2}{*}{$\mathrm{RC} \leq 20 \%$} \\
\cline { 2 - 3 } & Culture medium & 0.40 & \\
\hline \multirow{3}{*}{$1 \mathrm{~B} 8 \mathrm{Mab}$} & Final formulation of purified product & 99.39 & \multirow{3}{*}{ RC 85-115\% } \\
\cline { 2 - 3 } & Active pharmaceutical ingredient & 98.36 & \\
\cline { 2 - 3 } & Culture supernatant & 91.96 & \\
\cline { 2 - 3 } & Degraded sample & 78.29 & \\
\hline
\end{tabular}

$\mathrm{RC}$ - relative cytotoxicity

A

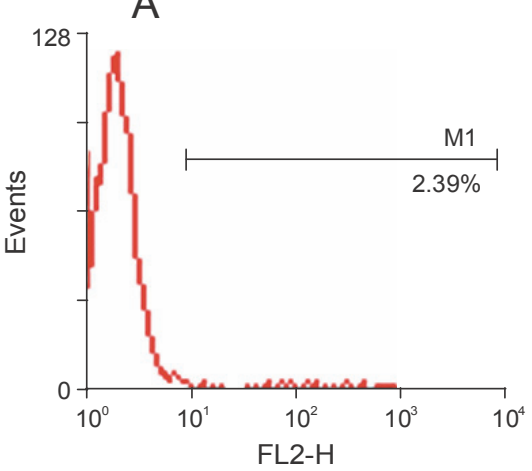

C

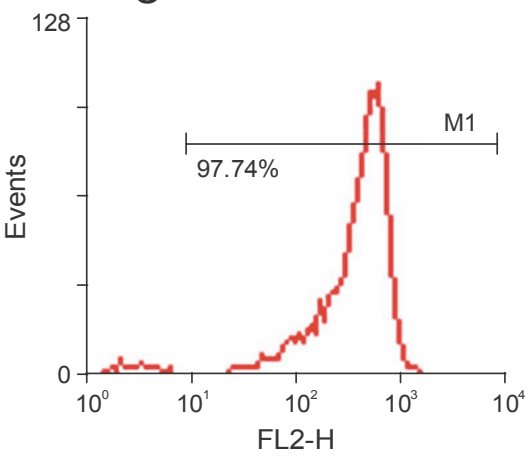

B

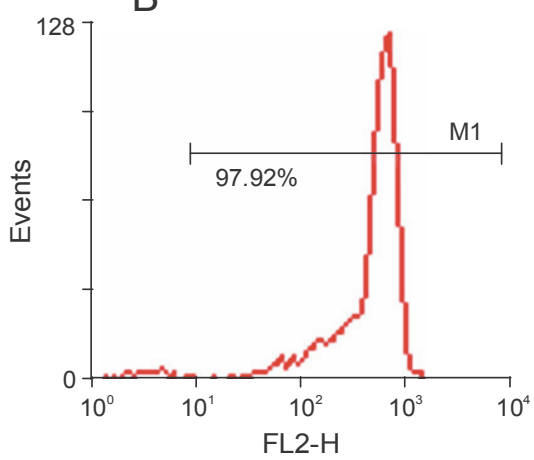

D

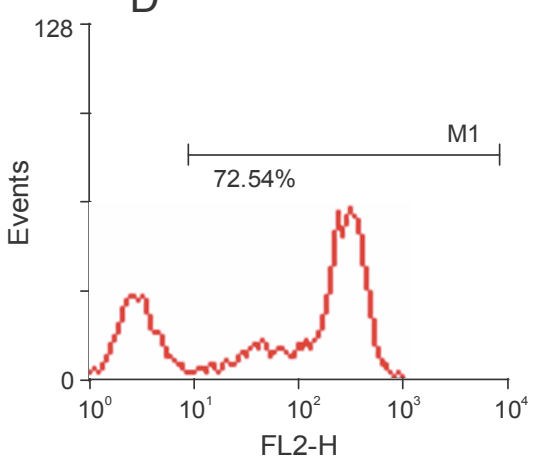

Pistatining

Fig. 4. Typical cytometric profiles of the complement-dependent cytotoxicity of 1B8 Mab obtained in a specificity assay. Histograms showing the discrimination of non-viable Ramos cells (M1) using the propidium iodide (PI) staining (FL2-H). Ramos cells treated with isotype control (itolizumab) (A), active pharmaceutical ingredient (B), final formulation of purified product (C) and degraded sample of 1B8 Mab (D)

In our study, the source and dilution of human complement were found to be critical in the $\mathrm{CDC}$ assay of Rituximab (FDA BLA 97-0244). As it is well known, AB blood group is traditionally used in CDC assays as well as in any immunological probe, possibly, to avoid the potential interference of anti-A and/or anti-B antibodies present in other blood groups. In this way, we assessed the potential impact, on sample toxicity, of different sources of human complement and blood groups covering the possible future changes in the serum source. In all cases, the relative cytotoxicity of 1B8 Mab fulfilled the acceptance criteria (85-115\%) - Table 5. Our results suggest that there are no interferences of the $\mathrm{ABO}$ blood group or Rh factor in the 1B8 Mab CDC assay.

In order to evaluate the potential impact of the sample acquisition order in the subsequent data analysis, the 


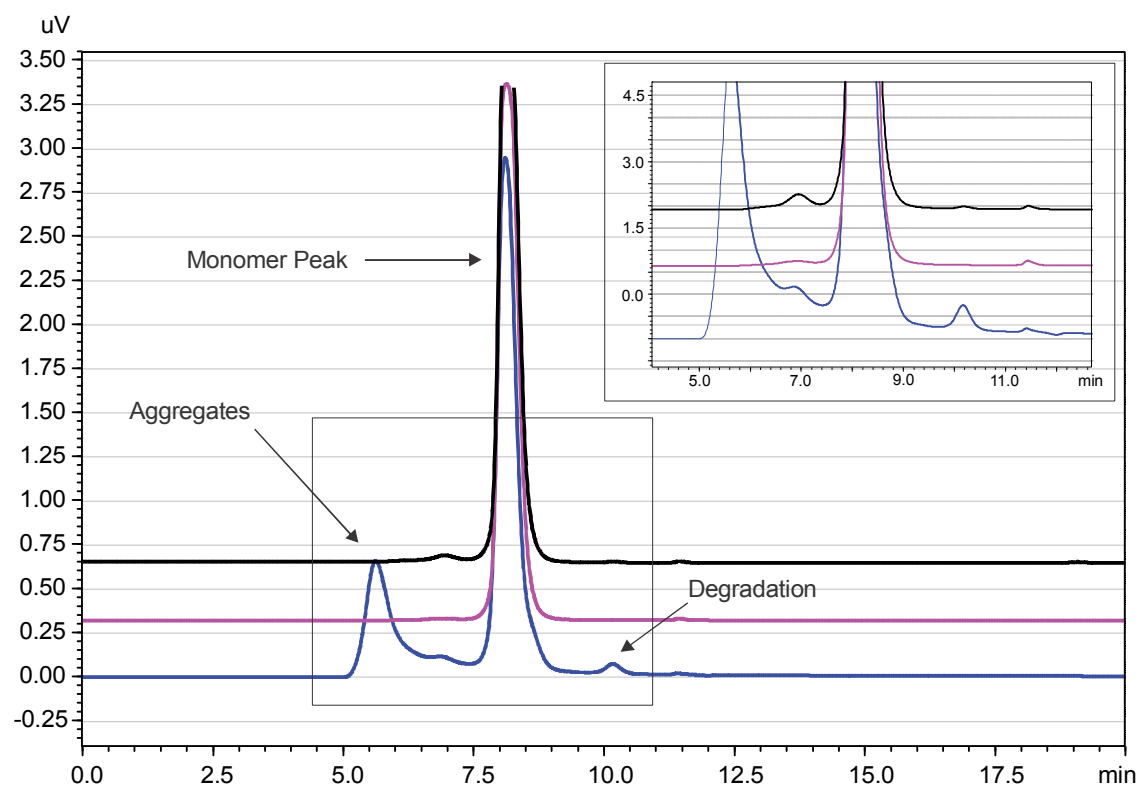

Fig. 5. Chromatographic profiles of $1 \mathrm{~B} 8 \mathrm{Mab}$ obtained by gel filtration-HPLC. Chromatographic profiles of the internal reference standard (black), final formulation of purified product (pink) and degraded sample of 1B8 Mab (blue)

Table 7. Repeatability results of relative cytotoxicity of $1 \mathrm{~B} 8 \mathrm{Mab}$

\begin{tabular}{c|l|c|c|c|c}
\hline \multicolumn{2}{c|}{ Samples } & RC & SD & CV & $\begin{array}{c}\text { Acceptance } \\
\text { criteria }\end{array}$ \\
\cline { 1 - 5 } 1 1B8 Mab & Final formulation of purified product & 101.32 & 0.96 & 0.95 & \multirow{2}{*}{ CV $\leq 15 \%$} \\
\cline { 2 - 5 } & Culture supernatant & 92.82 & 0.83 & 0.90 & \\
\hline
\end{tabular}

$\mathrm{RC}$ - average of relative cytotoxicity; SD, standard deviation; $\mathrm{CV}$, coefficient of variation

Table 8. Intermediate precision results of relative cytotoxicity of 1B8 Mab

\begin{tabular}{c|c|c|c|c|c}
\hline \multirow{2}{*}{ Measure } & \multicolumn{2}{|c|}{ Analyst 1 } & \multicolumn{2}{c|}{ Analyst 2 } & \multirow{2}{*}{$\begin{array}{c}\text { Acceptance } \\
\text { criteria }\end{array}$} \\
\cline { 2 - 5 } & FFPP & CS & FFPP & CS & \\
\hline RC & 101.49 & 94.53 & 98.10 & 94.75 & \\
\hline SD & 1.29 & 1.77 & 1.38 & 6.13 & \\
\hline CV & 1.27 & 1.87 & 1.41 & 6.47 & CV $\leq 20 \%$ \\
\hline
\end{tabular}

FFPP - final formulation of purified product; CS - culture supernatant;

$\mathrm{RC}$ - relative cytotoxicity; SD - standard deviation; CV - coefficient of variation

relative cytotoxicity was compared in nominal and random assays. In the last one, both, the order of samples application and the order of samples analysis in the flow cytometry were randomized. Similar results were obtained in nominal and randomzied assays with relative cytotoxicity values of 100.62 and $100.77 \%$, respectively. Therefore, the time that elapses between the end of the experiment and the end of flow cytometry acquisition seems to have no impact on the relative cytotoxicity of 1B8 Mab.

Specificity is usually defined as the ability to detect the analyte of interest in the presence of components that are expected to be present (ICH, 2005; Walfish, 2006). To determine the CDC assay specificity, samples containing suspected interferences (excipients used in the culture medium and in buffer formulation) were ana- 
lyzed in the presence and the absence of the analyte of interest. As expected, very low relative cytotoxicity activities was seen in the samples with no 1B8 Mab (less than $2 \%$ for isotype control Mabs and Mab-free matrix solutions). On the contrary, samples containing the 1B8 Mab, including the final formulation of a purified product, an active pharmaceutical ingredient and culture supernatant, were capable of inducing specifically CDC (85-115\% of relative cytotoxicity activity) - Table 6; Figure 4 . These results demonstrate the high specificity of the CDC assay of 1B8 Mab.

The percentage of relative cytotoxicity obtained with degraded (incubated at $60^{\circ} \mathrm{C}$ for $168 \mathrm{~h}$ ) sample of $1 \mathrm{~B} 8$ Mab was lower than that evidenced with non-degraded molecule (the same batch of a product but maintained at $\left.2-8^{\circ} \mathrm{C}\right)$ - Table 6 . This result suggests that the native conformation of 1B8 Mab was altered during the degrading process with an impact on the biological activity. To confirm the 1B8 Mab degradation, gel filtration-HPLC were performed (Fig. 5). The changes observed in the chromatographic profile of the degraded 1B8 Mab sample confirmed the presence of an additional peak corresponding to dimers and multimers species (products of aggregation) as well as a degradation peak. The degradation profile of 1B8 Mab was also confirmed by SDSPAGE (data not shown).

The most important part of any analytical method of validation is the precision analysis (repeatability and intermediate precision) (Walfish, 2006). The precision of an analytical procedure is usually expressed as a variance, $\mathrm{SD}$ or $\mathrm{CV}$ of a series of measurements $(\mathrm{ICH}$, 2005). Here, the repeatability (intra-assay variability) was evaluated using six sub-samples with three replicates of both final formulations of the purified product and culture supernatant. Individual assays ( $N=6$ each) were performed and the relative cytotoxicity, $\mathrm{SD}$ and $\mathrm{CV}$ were determined. The $\mathrm{CV}$ was $<1 \%$, which is considered acceptable (Table 7). The intermediate precision parameter usually expresses the within-laboratory variations, for example, different days and different analysts (Walfish, 2006). In the present study, the intermediate precision (inter-day and inter-person variability) was assessed by two analysts in three independent assays. The summary of these results is shown in Table 8 .

The precision of an analytical method should not exceed 15\% of the CV (FDA 2001) although, for flow cytometry binding assay the general criteria with CV $<20 \%$ (intra-assay variability) and $<25 \%$ (inter-assay variability) they are considered acceptable (Findlay et al., 2000). In our study, the relative cytotoxicity ( $N=9$ for each analyst and type of product) was found in the range between 85 and 115\% in all assays and the inter-assays and inter-analysts $\mathrm{CVs}$ were less than $7 \%$. In another validation study of a flow cytometry-based assay to measure the CDC activity of Rituximab, Cvs $\leq 30 \%$ to precision parameter were considered acceptable, although the CVs obtained were $\leq 7 \%$ (Herbrand and Scotti, 2007). In this way, the degree of precision obtained in our flow cytometry-based assay to measure the CDC activity of the $1 \mathrm{~B} 8 \mathrm{Mab}$ was found to be satisfactory.

\section{Conclusions}

In the present work we reported a validation study for the simple and sensitive flow cytometry-based assay, used for the determination of complement-mediated cytotoxicity of a novel anti-CD20 biosimilar candidate antibody (1B8 Mab). The validation study was performed in accordance with the $\mathrm{ICH}$ guidelines and under current good manufacturing practices (cGMP). The assay demonstrated to be robust for all factors evaluated. It also showed a high level of specificity and was found to be free of interference through the validation process. The degree of precision (repeatability/intermediate precision) obtained in this study was satisfactory. This flow cytometry-based cytotoxicity assay seems to be a useful and adequate technique in the lot-to-lot quality control of the culture supernatant and active pharmaceutical ingredient of 1B8 Mab. The development of a potency assay for the final formulation of a purified product of $1 \mathrm{~B} 8$ Mab using a similar flow cytometry-based procedure is ongoing in our lab.

\section{Acknowledgements}

The authors would like to express their gratitude to Denise Dorvignit, M.Sc (Immunobiology Department), for providing the Mabthera ${ }^{\circledR}$ and the human Burkitt's lymphoma cell line Ramos. The authors are also grateful to Mr. Antonio Vallin and to Idania Suarez López-Gavilán, B.Sc, for the critical revision of the manuscript and the editorial assistance, respectively. This work was supported by the Center of Molecular Immunology, Havana, Cuba.

\section{References}

Abid N.B.S., Rouis Z., Nefzi F., Souelah N., Aouni M. (2012) Evaluation of Dimethylthiazol Diphenyl Tetrazolium Bromide and Propidium Iodide Inclusion Assays for the Eva- 
luation of Cell Viability by Flow Cytometry. J. Appl. Pharm. Sci. 2(5): 10-14.

Blanco R., Cedeńo M., González N., Rodríguez R., Sánchez J., Rengifo E. (2012) Phenotypic heterogeneity in the NCI$H 125$ cell line affects biological activity using the epidermal growth factor receptor as target. Acta Pharm. 62: 581591.

Cedeńo-Arias M., Sánchez-Ramírez J., Blanco-Santana R., Rengifo-Calzado E. (2011) Validation of a Flow Cytometry Based Binding Assay for Evaluation of Monoclonal Antibody Recognizing EGF Receptor. Sci. Pharm. 79(3): 569-581.

Chu R. (2009) Biogenerics or Biosimilars? Discussing the Present, Considering the Future. Stockholm Network.

Dorvignit D., Palacios J.L., Merino M., Hernández T., Sosa K., Casaco A., López-Requena A., Mateo de Acosta C. (2012) Expression and biological characterization of an antiCD20 biosimilar candidate antibody: $A$ case study. Mabs 4(4): 488-496.

Ermer J. (2001) Validation in pharmaceutical analysis. Part I: An integrated approach. J. Pharm. Biomed. Anal. 24: 755767.

Enter J., Monson M. (2005) Evaluation of cellular viability with propidium iodine or 7-amino-actinomycin D. Cell. Anal. Bussin. Center, Beckman Coulter, Inc, 33196.

European Medicines Agency (EMEA) (2008) Guideline on human cell-based medicinal products. Available in: http:// www.emea.europa.eu/docs/en_GB/document_library/ Scientific_guideline/2009/09/WC500003894.pdf

Ederveen J.C. (2010) A Practical Approach to Biological Assay Validation. Progress report number 08090.

Findlay J.W.A., Smith W.C., Lee J.W., Nordblom G.D., Das I., DeSilva B.S., Khan M.N., Bowsher R.R. (2000) Validation of immunoassays for bioanalysis: a pharmaceutical industry perspective. J. Pharm. Biomed. Anal. 21: 1249-1273.

Food and Drug Administration (FDA) (2001) Guidance for Industry. Bioanalytical Method Validation. Available in: http://www.fda.gov/downloads/Drugs/GuidanceComplia nceRegulatoryInformation/Guidances/ucm070107.pdf

Fernández-Marrero Y., Roque-Navarro L., Hernández T., Dorvignit D., Molina-Pérez M., González A., Sosa K., LópezRequena A., Pérez R., de Acosta C.M. (2011) A cytotoxic humanized anti-ganglioside antibody produced in a murine cell line defective of $\mathrm{N}$-glycolylated-glycoconjugates. Immunobiology 16(12): 1239-1247.

Food and Drug Administration (FDA) Center for Biologics Evaluation and Research. BLA 97-0244 (Genentech). Available in: http://www.fda.gov/downloads/Drugs/ Deve lopmentApprovalProcess/HowDrugsareDevelopedandA pproved/ApprovalApplications/TherapeuticBiologicAppl ications/ucm107743.pdf

Herbrand U., Scotti S. (2007) Analytical Methods. European Biopharmaceutical Review. Available in: http://www. samedanltd.com//?mod=magazine\&id=12\&page=article \&issid=169\&pid=3210\&post

International conference on the harmonization (ICH) (1999) Specifications: test procedures and acceptance criteria for biotechnological/biological products. Q6B. Available in: http://www.ich.org/fileadmin/Public_Web_Site/ICH_Pr oducts/Guidelines/Quality/Q6B/Step4/Q6B_Guideline.pdf

International conference on the harmonization (ICH) (2005) Validation of analytical procedures, Q2 (R1): Text and Methodology. Step 4. Available in: http://www.ifpma.org/ ich1.html

Smith M.R. (2003) Rituximab (monoclonal anti-CD20 antibody): mechanisms of action and resistance. Oncogene 22: 7359-7368.

Vander H., Nijhuis A., Smeyers-Verbeke J., Vandeginste B.G.M., Massart D.L. (2001) Guidance for robustness/ ruggedness test in methods validation. J. Pharm. Biomed Anal. 24: 723-753.

Walfish S. (2006) Analytical Methods: A Statistical Perspective on the ICH Q2A and Q2B Guidelines for Validation of Analytical Methods. BioPharm International. Available in: http://statisticaloutsourcingservices.com/Methval.pdf

Winiarska M., Bil J., Wilczek E., Wilczynski G.M., Lekka M., Engelberts P.J., Mackus W.J.M., Gorska E., Bojarski L., Stoklosa T. et al. (2008) Statins impair antitumor effects of Rituximab by inducing conformational changes of CD20. Plos Medicine 5(3): 0502-0517. 